\title{
UCLA
}

Mester

Title

Conversaciones con Sergio Ramírez

Permalink

https://escholarship.org/uc/item/68t3c0mn

Journal

Mester, 32(1)

Authors

Alcántar, lliana

Arsova, Jasmina

Publication Date

2003

DOI

10.5070/M3321014587

Copyright Information

Copyright 2003 by the author(s). All rights reserved unless otherwise indicated. Contact the author(s) for any necessary permissions. Learn more at https://escholarship.org/terms

Peer reviewed 


\section{Conversaciones con Sergio Ramírez}

Iliana Alcántar y Jasmina Arsova

University of California, Los Angeles

Del 6 al 14 de febrero de 2003 Sergio Ramírez (Nicaragua, 1942), reconocido novelista y destacado político, estuvo en la Universidad de California, Los Ángeles como invitado de honor de la serie especial University of California Regents' Lectures, conferencias auspiciadas por la Oficina del Rector y el Departamento de Español y Portugués. Durante su estancia Ramírez le concedió a Mester una generosa entrevista, la que a continuación presentamos y en la cual el autor de Margarita, está linda la mar, y Sombras nada más, comenta ampliamente sobre el proceso creativo, la influencia de la cultura popular en su obra, el compromiso del autor, la identidad, y sus preferencias literarias, entre otros temas.

Mester: Debido al reciente fallecimiento del escritor guatemalteco Augusto Monterroso (1921-2003), Elena Poniatowska dijo: “El mejor homenaje para él es leerlo, enseñarlo, conocerlo, creo que la única manera de honrar a un escritor es leerlo y divulgar su obra". Tomando eso como punto de partida, ¿a qué autores hispanoamericanos se les debe rendir homenaje en la actualidad, o a qué autores les rinde usted homenaje?

Sergio Ramírez: Bueno, empezando por Tito Monterroso, creo que él es el ejemplo cabal de lo que debe de ser el escritor latinoamericano, y él quizá llevó al extremo esta característica de que un escritor se define no sólo por lo que escribe sino también por lo que no escribe, en el sentido que él en la escogencia de sus temas, en la brevedad de su obra, en la parquedad de palabra fue desechando todo lo que ha tenido de retórico la literatura latinoamericana, de inservible, de ocioso o de sobrante. Kafka decía algo muy cierto y es que el arte de escribir es también el arte de suprimir. Y Tito fue muy experto en eso de desechar temas e irse quedando con la esencia articulada 
de la palabra. En uno de sus escritos él dice con mucha ironía "hoy terminé una línea, hoy me siento un Balzac.” Y esto demuestra esta depuración o esta destilación permanente de los temas, del lenguaje, y sólo tratar de decir lo esencial. Me parece que en este sentido es ejemplar Monterroso en nuestra literatura. Hay otros que son muy buenos por todo lo contrario, por su gran exhuberancia como el caso de Alejo Carpentier, como en el caso de Gabriel García Márquez, u otros porque en la perspectiva de la literatura también tratan de aleccionar, digamos en términos éticos a través de la historia como en el caso de Carlos Fuentes. Esto viene mucho del idealismo de la literatura alemana, desde siempre. O porque se tratan de construir frisos móviles de la historia, como en el caso de la obra de Balzac, esa novela ecuménica que toca todos los temas y que trata de reproducir la realidad en términos de la imaginación pero sin ahorrar escondrijos de la historia, sin ahorrar esquinas oscuras y que va desarrollándose frente a nuestros ojos verdaderamente como si fuera un rollo de película, como si fuera un friso. Esto tiene que ver también con la vocación, por la brevedad de la que hablaba Tito, por la esencia de las palabras, por no fijarse más que en la esencia y dejar de lado los desperdicios, y en otro sentido por esta gran vocación ecuménica que tiene la literatura latinoamericana. Entonces yo lo vería como un péndulo que se mueve entre estos dos extremos: el arte extrayéndole su esencia, y el arte como una exposición total de la realidad.

M: El mismo Monterroso comentó: "Nunca he llegado a saber cómo se escribe un cuento. Incluso le tengo prevención a ese conocimiento. Tengo el prejuicio o la superstición de que si llego a saber cómo se hacen los cuentos, pasaría de ser un artista a un artesano, y entonces podría hacer uno cada ocho días. Pero como no sé cómo se hacen, sigo a merced de lo que vaya cosechando en cada ocasión." Esto me parece más bien una forma de eludir el compromiso de ventilar el proceso de la creación literaria, la cual los críticos siempre quieren conocer. Pero, ¿no le parece un poco egoísta el no querer revelar "los secretos de cocina" de los que nos hablaba el jueves? $O$, ¿por qué la renuencia de dejarle ver al lector las costuras de la confección literaria?

SR: Esto depende de cada escritor. Creo que cada escritor tiene un plan divino de la creación, cada escritor es su propio dios en su propio universo y puede ser que un escritor parta de un mapa muy 
detallado de toda su obra y utilice un esquema de personajes, incluso pueda llegar a definir una novela de manera previa por capítulos, lo que va a decir cada capítulo y ya tener resuelto el desenlace. Ésos son los escritores para mí más felices. Yo desgraciadamente no pertenezco a esa categoría donde todo está previamente resuelto, aunque los existen y son muy buenos. Para mí una obra literaria tiene dos aspectos, el de la exploración a oscuras a medida que uno se adentra, un viaje muy a oscuras; uno va navegando tal vez con una idea de norte, pero sin saber exactamente a qué puerto va a llegar. Y por otro lado, están los secretos técnicos del oficio, eso es diferente. A mí me gusta mucho explicarle a los más jóvenes cuáles son las piedras en la cuales no hay que tropezar, cuáles son los caminos que hay que seguir en cuanto a la técnica de escribir, cómo cuidarse de los errores. Pero en cuanto a enseñar a navegar, eso es imposible. Es decir, decirle a alguien, "bueno, para que tú escribas una novela tienes que hacer como yo hago". Eso sería, me parece, algo muy pretencioso porque los caminos sólo los da la propia imaginación y son muy complejos, pero sí existen unas técnicas que son absolutamente artesanales, y la artesanía sí se puede enseñar. Lo que no se puede enseñar es cómo ver en la oscuridad.

M: Si Ud. pudiera imaginar un canon literario sincrético hispanoamericano, ¿cómo sería? ¿Se incluiría usted en ese canon? Porque hay excelentes autores de Latinoamérica que no caben por una causa u otra dentro de un canon, y es una lástima que no se incluyan.

SR: A mí me gustaría tomar dos polos muy distintos como son Rulfo y Borges porque son dos escritores que fueron para mí esenciales durante mis años de formación, en mis tempranos veinte años o al final de mi adolescencia. Primero porque Rulfo a mí me enseñó a ver el mundo rural, que sigue siendo una realidad ineludible. América Latina sigue siendo un continente muy rural, de una cultura muy rural y eso tiene muchísimo trasfondo. Me enseñó a ver el mundo rural desde una perspectiva nueva, porque el mundo rural desde la literatura vernácula se contemplaba desde arriba, desde el balcón académico y cuando un escritor bajaba al mundo rural, al mundo indígena, lo hacía poniéndose antes como guantes quirúrgicos, asépticos, y tocaba las palabras con cuidado de no contaminarse. Fíjense bien que un escritor de los años veinte, los años treinta, el 
lenguaje vernáculo lo pone entre comillas, y es una toma de distancia, como decir "Yo nada tengo que ver con esto," "eso es cosa de ellos". Rulfo terminó con eso, se bajó del balcón académico, se metió entre la gente y comenzó a hablar desde el pueblo, eso me parece que fue muy trascendental. Y por otro lado Borges a mí me enseñó que la imaginación no tiene límites, que uno puede articular, en busca de la verosimilitud una apariencia de veracidad absoluta a costa de cualquier mentira, de fabricar hasta las bibliografías, las literaturas germánicas, las literaturas nórdicas, que en literatura, en el campo de la invención todo se vale, que toda mentira es legítima.

\section{M: Usted publicó su primer libro de cuentos en 1963, ¿no?}

SR: [En el año] 63, cuando tenía 21 años.

M: ¿Podría comentar sobre qué lo llevó a la literatura, y sobre todo a publicar tan joven?

SR: A mí me gusta repetir como Isaac Bashevis Singer que uno escribe por necesidad. Uno debe sentir esa necesidad absoluta de contarle a los demás lo que uno siente que vale la pena contar. Ése me parece que es el principio de toda vocación narrativa. Creo que si no se siente esa necesidad pues uno no tiene ese llamado, esa vocación, ese don, o como queramos llamarle. Yo empecé a escribir mis primeros cuentos desde que tenía 17 años y sentí que yo me estaba decantando además en Nicaragua, hacia la narrativa, que no era un campo muy explorado, dejando de un lado la poesía, que es el camino de entrada de todo el mundo en América Latina a la literatura, pero especialmente en Nicaragua por la gran tradición marcada por Rubén Darío. Escribí poemas en la adolescencia, pero la verdad es que cuando reuní mis cuentos yo estaba decidido a publicar un libro de cuentos y nunca se me ocurrió un libro de poesía; entonces yo sabía que ése era mi camino, y los temas que comencé a tocar fueron los de la realidad más inmediata al tratar de carnavalizar (como se dice ahora en la teoría literaria), la realidad, viéndola con ironía, tomando la distancia del humor, y a tocar también los temas cotidianos que para mí eran dramáticos. El primer cuento que yo escribí realmente se llama "El estudiante," que ilustra la situación en que un estudiante de aquellos años tiene que regresar a su provincia de origen 
y después de dejar en una casa de empeño sus libros, su anillo de secundaria, de bachillerato, porque la vida lo ha derrotado, porque su padre se ha visto envuelto en una de las conspiraciones contra Somoza, nadie puede mantenerlo en la universidad, entonces tiene que regresar derrotado. Ésa es la primera historia que yo escribí porque es la que yo tenía de frente, y me pareció extraordinaria. Es lo que les decía, sentí la necesidad de decir, "Ve, esto me parece que es singular, me parece que hay que ponerlo por escrito, y a otros les va a interesar". Ése me parece que es el principio de la escritura.

M: En cuanto a influencias literarias, ya mencionó a Borges, Rulfo, y también a Vargas Llosa. ¿Cuáles serían otros autores que influyeron en sus lecturas de juventud?

SR: Para formarme como cuentista primero para mí fue muy importante mi lectura de Chejov. Sus cuentos me abrieron el universo de lo que yo quería decir, de lo que yo quería hacer, de quedarme siempre en el territorio de los pequeños seres, que es lo que más me encanta de Chejov: la gente anónima, esta cosa tan trágica. Pero Chejov la ve siempre con aire burlón, por ejemplo el hecho que según las ordenanzas de Pedro II los burócratas se tuvieran que vestir de uniforme, o que estaban divididos en catorce categorías, ese mundo anónimo, gris, pero lleno de gracia y de pequeñas sorpresas. Los cuentos de Maupassant, de O. Henry, un escritor que a mí me influyó mucho (ahora bastante olvidado en EE.UU.), que para mí es un clásico para leerlo y tratar de aprender con él cómo se monta y se desmonta un cuento en su mecanismo de relojería. Leía en ese tiempo muy intensivamente los cuentos de Edgar Allan Poe y también los de Faulkner, los de Hemingway, ésas fueron mis lecturas de antes de los 20 años.

M: El epígrafe del libro más reciente de García Márquez dice: “La vida no es la que uno vivió, sino la que uno recuerda y cómo la recuerda para contarla”. ¿Es ésa la misma línea que usted siguió en Adiós muchachos?

SR: En Adiós muchachos hay dos líneas narrativas: una lo que yo recuerdo, lo que me parece más singular de mis recuerdos pero digamos con un filtro político. Porque yo no quería escribir un libro 
amargo, no quería escribir un libro contestatario, un libro de denuncia, sino un libro sentimental, un libro de mis recuerdos personales de la revolución, mi vida, la de mi familia, cómo me metí a la revolución, cómo salí. Y luego, por otro lado, en capítulos alternos hacer un juicio de mis ideas sobre la revolución, de lo que fue, de lo que pudo ser, de dónde se falló, de cómo era el mundo en los años setenta cuando la revolución se desató en Nicaragua, y cómo era el mundo cuando terminó y lo ejes fundamentales en los cuales se movió la revolución, el conflicto con la iglesia, el conflicto con los capitalistas, el conflicto con EE.UU., la importancia de la religión, del cristianismo en la revolución, la confrontación este-oeste, cómo estuvimos colocados nosotros, es decir, los errores fundamentales de concepción, el peso de la ideología. Todo eso me interesaba también analizarlo, entonces yo diría que esto es un pájaro que vuela mediante dos alas, la de los recuerdos y la del análisis.

M: ¿Es mucha la tentación de caer en la creación del artificio cuando se intenta narrar una biografía?

SR: Cuando un novelista escribe sus memorias tiene siempre la tentación de la invención porque eso es una deformación profesional, y cuando uno no encuentra un dato pues, $¡$ a reponerlo con la imaginación! Yo trato de evitar en Adiós muchachos esta tentación porque se trata en primer lugar de un acto de honestidad conmigo mismo, y en segundo lugar porque son hechos tan recientes que cualquier cosa que yo diga imaginativa puede ser comprobable. Y además se trata de escribir algo que sea transparente en el sentido que las cosas se dieron como yo las vi, obviamente, ¿no? Nunca existe la verdad absoluta, a mí siempre me gusta recordar el ejemplo de Bernal Díaz del Castillo en su Historia verdadera de la conquista de la Nueva España, cuando él da su memoria de soldado de cómo él vio porque él participó y no quiere que le vengan a contar cómo se escribió la historia de la conquista de México a alguien que no la vivió, como López de Gómara.

M: Lo visto y lo vivido versus lo contado...

SR: Exactamente, ésa es mi primera presunción. Ahora, yo creo que cuando uno escribe sus memorias de la infancia, de la juventud, uno entra en un territorio bastante resbaloso. Como dice L. P. Hartley, 
"El pasado es siempre un país extranjero," y la gente que vive en ese país tiene otras costumbres; entonces uno entra a ese territorio, y al de la infancia, se sumerge en ese territorio y cuando sale, con la pes$\mathrm{ca}$, trae peces de todos los colores, pero algunos son verdaderos y otros no. Y la memoria y la imaginación van corrigiendo el pasado; la memoria se va tiñendo siempre de imaginación, es inevitable que se confunda memoria con imaginación porque son dos criaturas que viven juntas en el subconsciente, entonces se van prestando colores una a otra. Esto es muy difícil, si a mí me preguntan, ¿cuál es su primer recuerdo de la infancia? Digo, bueno, recuerdo que debo haber tenido tres años cuando siento que la muchacha que me bañaba me levanta de una enorme pana y me pone sobre una máquina de coser y me envuelve en una toalla, pero yo he recordado tanto esa escena que - y además como tengo la deformación cinematográfica - yo me rodeo como con una cámara me voy viendo de todos los lados, y me estoy viendo fuera de mí mismo; entonces eso ya la imaginación está traspasada a una técnica que es la técnica del cine. Puede ser que a uno le cuentan cosas de su infancia y luego las incorpora a la memoria, como que realmente las recuerda, pero un escritor no tiene por qué preocuparse de eso, al fin y al cabo lo que trasponga a la página literaria es lo que va a quedar.

M: Si pudiera rescribir su vida desde la juventud en adelante, ¿cambiaría algo?

SR: No, no cambiaría nada, en absoluto. Creo que eso es una cosa un poco faústica, siempre estar pidiéndole al destino volver a empezar, no, yo estoy muy conforme. Creo que si cada vez volviera a empezar mi vida en un momento determinado, seguramente volvería a hacer exactamente lo mismo. Porque me parece que uno de los grandes errores que uno puede cometer es tratar de comenzar de nuevo en la vida pero teniendo la experiencia que ahora tiene y tratando de corregir mediante la conveniencia que le da haber vivido y decir "Esto no lo volvería a hacer," eso es imposible. Porque el pasado siempre se va a reproducir entero, a la edad que uno tenía, con la experiencia que tenía, con las ilusiones que tenía, y desgraciadamente uno va perdiendo en el camino ilusiones, eso es inevitable y la edad de la historia de entonces, cómo era el mundo y todo eso es lo que lo impulsa a uno a tomar determinado paso en cada momento. 


\section{M: ¿Y no borraría nada de su actividad política?}

SR: Es lo mismo, ¿no? Y ahí con mucha más razón. Yo ahora podría dar cátedra y decir "Estas cosas no se debieron haber hecho así," "yo si volviera a comenzar las haría de otro modo," pero repito lo mismo, tendríamos que estar en 1979 con las condiciones que había entonces, con las creencias que había entonces, con las esperanzas que había entonces, y con la edad que yo tenía entonces. Nadie se mete a una revolución a los 60 años de edad.

M: Eventualmente, : piensa escribir sus memorias, hacer un recuento de sus vivencias personales, que no solamente incluya sus tiempos en la revolución, sino lo que aconteció antes y después de ella?

SR: Yo tengo escritos mis recuerdos de hasta que salí de mi pueblo a los 17 años a estudiar a la universidad, pero es un libro que no tengo ningún interés en publicarlo, no me siento que esté en la edad de comenzar a ver hacia atrás. Lo he hecho como un ejercicio y sí, es un libro donde yo hablo de mi familia, del ambiente en que crecí, de mi encuentro con el cine, con la literatura, con los cómics, con las radionovelas que son lo que a mí me formó como escritor.

M: ¿Es algo que se va a quedar dentro del mundo más íntimo de su familia?

SR: No, alguna vez eso lo voy a publicar, pero no tengo ninguna urgencia de dedicarme a publicar memorias. Es un libro que se llama Retrato de familia con volcán, porque en mi pueblo desde cualquier parte se divisa el volcán Santiago, un volcán muy alto. Y siempre viniendo hacia mi casa desde la parte más alta del pueblo ese volcán se divisa como si estuviera en el patio de mi casa.

M: ¿Podría compartir una memoria vital de su vida - literaria o no - que le haya afectado el alma de escritor, algo especial que recuerde?

SR: Un hecho que definió mi vida ocurrió precisamente en 1959, el año que yo viví en la universidad cuando el dictador Somoza disparó en contra de una manifestación de estudiantes en la que yo 
participaba. Yo soy sobreviviente de esa tarde cuando mataron a cuatro compañeros míos y detuvieron a más de sesenta. Es un hecho que a mí me marcó para toda la vida. Es un hecho decisivo en mi vida. Eso me hizo a mí adquirir un compromiso conmigo mismo de luchar contra la dictadura. Bueno, esa lucha duró 20 años, este hecho se dio el 23 de julio de 1959. Y el derrocamiento de Somoza se produjo el 19 de julio de 1979.

M: Los versos de los poemas de Darío que dan título a muchos de los capítulos de Margarita, está linda la mar, ¿fueron escogidos al azar o tienen algún significado especial en su vida? ¿Cuál fue el proceso de selección?

SR: Son escogidos por mi memoria porque yo me sé tanto a Darío que podía tener un repertorio como para ir a dar con los versos que yo quería que representaran cada capítulo. Porque lo hacía al azar de la memoria y de poemas en donde uno podría pensar que no resultaría nada o que son muy ajenos, como el poema que dedica Darío a Juan Ramón Jiménez, donde le pregunta si está listo para ser poeta. Es un poema muy bello, una verdadera ars poetica. Entonces fui tomando estos versos de muy distintos poemas para que se acoplaran a la intención de cada uno de los capítulos. Desde luego que ésta es una novela muy dariana, está escrita en función de Darío y del modernismo.

M: Si el poeta es un pequeño dios, ¿qué es el novelista?

SR: Quizás un dios mucho más omnímodo. Porque por lo menos el novelista es un dios omnipresente. Siempre me da curiosidad examinar estas ideas porque realmente el papel primario del novelista es el del dios omnisciente, y todas la novelas se podrían escribir en clave de omnisciencia. Es decir, uno lo sabe todo, lo conoce todo, puede dominar todas las vidas, entrar en todos los escenarios, levantar los techos de las casa como hace El diablo cojuelo de Vélez de Guevara, o meterse por todas las calles, en las conciencias, o manejar grandes ejércitos como hace Tolstoi en La guerra y la paz. Pero bueno, también uno en esa función de dios a veces escoge la visión limitada, la visión del dios personal, del que no lo sabe todo, pero es dios que se finge que no sabe todo, y al final lo sabe todo. Ése es el papel de dios, 
que tiene poder de vida o muerte sobre sus personajes, y al fin y al cabo en la vida pues todos somos personajes de la novela que está escribiendo Dios, como diría Borges.

M: Existe una influencia de la música en su obra, y en particular los tangos y los títulos de éstos en su escritura, ¿cuál sería entonces la influencia de la música popular en su obra?

SR: Ésta es una influencia sentimental que se acumula en la juventud, en la adolescencia, es la música que uno aprendió y ya no la olvida más. Yo creo que en la adolescencia, en la infancia es cuando se aprende uno los poemas, que ya va a saber toda la vida, las canciones que va a poder repetir toda la vida, y los idiomas que va a hablar. Es muy difícil comenzar a estudiar un idioma ya viejo; se podrá, pero yo digo que es difícil. Esto es lo que se queda en la corteza cerebral y lo acompaña a uno siempre, y yo siempre tuve una gran afición por la música popular. A mí me parece que las letras de los boleros, de los tangos, contienen verdaderas novelas de amor encapsuladas, pero son verdaderas novelas de amor, o cuentos que relatan tragedias de amor, y muchas de ellas escritas en verdadero romance. Hay letras que son muy bellas, los tangos de Gardel y Lepera que son verdaderas poesías o las canciones de José Alfredo Jiménez que me encantan porque son verdaderos poemas, populares, pero son verdaderos poemas. Entonces las letras viven conmigo y la música también, es una especie de toque sentimental que devuelve muchos recuerdos siempre que uno oye una canción, le pasa no sólo a los escritores, le pasa a todo el mundo. Es como cuando Proust metía a Magdalena en la taza de té de tilo, entonces explotaban todos los recuerdos, entonces así me pasa a mí cuando oigo una música o canción de aquellos tiempos. Por otro lado, yo vengo de una familia de músicos, me gusta dividir el oído musical en oído activo y oído pasivo. Yo no sirvo para componer, no sirvo para entonar, soy muy desentonado, pero sí tengo el oído pasivo de recordar la música y tengo el oído musical de poder usar el ritmo de la música y la melodía de la música en la prosa, para mí la prosa tiene mucho que ver con el ritmo y con la melodía, tiene que tener un sentido musical.

M: En cuanto al tema del exilio voluntario o involuntario, a su juicio, ¿qué perspectiva le da el exilio a un escritor? ¿Cómo le sirve 
en su quehacer literario? ¿No es verdad que un autor se puede enriquecer de varias formas al estar fuera de su país?

SR: Creo que en primer lugar para un ser humano los exilios nunca son buscados. Son provocados por alguna circunstancia anormal (no sólo política, puede ser económica o de cualquier tipo), pero uno deja su estado natural y hay una ruptura cuando uno tiene que emigrar y que crea anímicamente también una anormalidad. Desata nostalgia, inconformidad, el dolor de la ausencia, - es un estado obviamente anormal - y quizá uno estando lejos de su país, y ya hablando como escritor, la nostalgia, la ausencia y la distancia pueden poner mucho más en relieve ciertas características o recuerdos que como uno los vería estando dentro del país. Ésta ya es una ventaja literaria de la ausencia o el exilio, o de la imposibilidad de volver, o de la dificultad de regresar a su propio país. Obviamente que la literatura encuentra ventajas en la desventajas, la ausencia, el exilio, son desventajas para un ser humano pero ventajas para un escritor que puede ver de manera más transparente y más cercana con los ojos del exiliado.

M: ¿Tiene usted algún autor del exilio? A Donoso por ejemplo, es difícil concebirlo sin ese exilio.

SR: El primer autor que tenía una visión del exilio que me impresionó y lo leí también en mi adolescencia fue Vintila Horia, escritor rumano con un libro muy bello que se llama Dios ha nacido en el exilio, que se ganó el premio Goncourt en Francia en el sesenta, comienzos de los sesenta. Otro es el caso del exilio de Ovidio al Ponto Euxino, - eso era lo que fue Rumania y Bulgaria, toda la parte del mar Negro - . Ese libro me impresionó por la visión del exiliado, de su nostalgia; de hecho Vintila Horia estaba exiliado entonces en París. Y me parece que la literatura latinoamericana es muy hija del exilio también, por los acontecimientos anormales que siempre ha vivido América Latina, mucha de la literatura latinoamericana ha sido escrita en los exilios. Como en el caso de Monterroso, el caso que mencionabas de José Donoso, en el caso de García Márquez, que escribió Cien años de soledad en México. Exilios virtuales porque nadie había expulsado a García Márquez de Colombia, pero las condiciones económicas, la búsqueda de nueva vida empujan a los escritores a otros territorios. 
M: ¿Dónde se incluiría usted, como parte de la identidad literaria centroamericana, en la literatura fundacional más amplia latinoamericana, o hispana incluyendo a España, o universal?

SR: Creo que las identidades se van confluyendo como esas muñequita rusas, una dentro de otra. Yo me siento primero nicaragüense, obviamente, me siento después centroamericano, después me siento latinoamericano, y después, mi patria es la lengua. Mi patria universal es la lengua, y allí sí es una patria inmensa que incluye todo el dominio de la lengua castellana. Pero, a mí me gusta decir también que la identidad existe mientras uno la busca, cuando la encuentra, entonces toda la aventura terminó. El hecho de tener una identidad es buscarla, estarse preguntando siempre "¿Qué somos?" Yo creo que en Europa mucha gente hace tiempo se dejó de preguntar "¿Qué somos?," son temas que no le interesan más. A nosotros sí, siempre nos interesa estarnos preguntando "¿Qué somos? ¿Qué pasa con un mexicano a este lado de la frontera?" Si sigue siendo mexicano o no sigue siendo mexicano, y siempre somos pueblo de migración, masiva incluso, ¿no? Los nicaragüenses que se van a Costa Rica aunque eso está allí nada más al otro lado, pero Costa Rica tiene otra cultura, otros niveles de vida, otro sistema de educación; entonces, ¿cómo cambia la gente? Eso para mí es un tema siempre fascinante: ¿cómo cambia en los viajes, en las migraciones, cómo su propia identidad se altera? A mí, me gusta leer los periódicos del exilio, de lo que sigue siendo el exilio porque en $\mathrm{Ni}$ caragua nadie está impedido volver ahora, pero ya las comunidades se quedaron como comunidades de exiliados. Me gusta leer los periódicos que se editan en Miami, y me encuentro que los productos que se anuncian en Miami (productos de comestibles) ya no existen en Nicaragua. Pero, al transponerse una cultura fuera de la frontera de un país se produce una especie como de anquilosamiento de la cultura, como de preservación natural. Hay cosas que se van quedando allí y que dejan de existir en el origen y quedan existiendo afuera, eso es fascinante en términos de la identidad cultural. Entonces esto es un escenario muy móvil, el de la identidad en América Latina. Yo realmente me siento muy identificado, y esto tiene que ver con la identidad de cualquier país latinoamericano, desde Argentina, Venezuela, México, a Chile, a Perú, Colombia; ya no se diga los países centroamericanos, que creo tienen una identidad mayor entre sí y por la proximidad geográfica, por su constante comunicación histórica, por las costumbres. Pero, bueno, 
también hay grandes diferencias, entre un costarricense y un nicaragüense hay muy pocas afinidades culturales, son dos universos vecinos, pero completamente diferentes; mientras la emigración masiva nicaragüense no comienza a transformar la cultura costarricense, porque eso es inevitable, ¿no? Va a ocurrir y ya está ocurriendo, y al costarricense no le gusta mucho, pero eso no lo puede evitar nadie. Porque la cultura nicaragüense es una cultura muy fuerte, muy agresiva, es decir, no es la mejor cultura como la que tienen los costarricenses, que tiene más alfabetización, son más civiles, tienen mejor trato, quizás, pero la cultura nicaragüense es más agresiva.

M: Podríamos establecer un paralelo con lo que ocurre aquí, con la inmigración constante se ha llegado a desestabilizar un mundo "ideal," de cierta forma...

SR: Claro, creo que la primera muestra de cómo una cultura va transformando al país que le da asilo, es cómo la gente transforma sus hábitos alimenticios, por ejemplo, eso es una buena muestra. La gente sin darse cuenta comienza comer de manera distinta y sus hábitos van variando. El hecho de que en todas las clases de la clase media costarricense haya una empleada doméstica nicaragüense, va imponiendo un cambio desde el gusto culinario. Y, es un cambio de identidad también, que la gente no va percibiendo pero después se da cuenta que, ya a la segunda generación, ya, sus hábitos de comer, de hablar, su manera de expresarse han ido cambiando. Quizás, en el impacto entre México y EE.UU. es diferente porque se trata de dos lenguas distintas. Hay una resistencia, por lo menos oficial, de la lengua inglesa frente a la lengua española y está el hecho de la cultura bilingüe. Pero entre Costa Rica y Nicaragua, por ejemplo, tratándose de la misma lengua la permeabilidad es mucho más rápida.

M: ¿Se podría decir entonces que es una identidad más sincrética?

SR: Sí, creo que son asuntos intercambiables, de identidad. Si a alguien en Nicaragua le preguntan, “¿Cuál es su aspiración de sistema de vida?," todo el mundo responde "Costa Rica". Aunque la gente hable mal de los ticos. Es una influencia permanente, el modelo democrático, el modelo del bienestar, eso es una aspiración, y claro las aspiraciones están dentro de las señales de la identidad. 
M: Si usted les pudiera aconsejar algo a los escritores que vienen de los países periféricos, ¿qué les sugeriría cuando se encuentran con los problemas de ser publicados, de ser leídos, conocidos fuera de sus propias regiones y nacionalidades?

SR: Lo primero es armarse de su lengua. Un escritor se equivoca si cree que no existe si no se le publica de inmediato. El trabajo de la literatura es un trabajo muy duro, muy serio y lo importante es escribir con autenticidad, saber que lo que uno está diciendo es verdadero para uno mismo. La verdad es otra cosa, la verdad política, la verdad ideológica, eso no me interesa a mí imponérselo a nadie ni tratar de definirlo. Sino la verdad que yo siento, en mi vida, lo que yo quiero transmitir como real, como verdadero. Me parece que el mundo, explorar allí, es un profundo, y muchas grandes literaturas son literaturas de inmigrantes, son como ya decíamos antes, literaturas hijas del exilio. Pero en otro sentido, y en el sentido que transponer a un ser humano que tiene la habilidad de escribir a un medio nuevo puede resultar en una gran literatura. Esto es un terreno muy delicado porque yo vuelvo a la autenticidad y a esa verdad interior; porque eso también tiene el riesgo de los clichés, de que te matriculen como representante de una cultura mixta y te vas a la superficialidad, eso a mí no me interesa, los clichés y los arquetipos baratos. Sino las literaturas que parten de la propia lengua, claro, a mí me interesan los escritores que se trasladan a un ambiente cultural distinto, a una lengua distinta y siguen escribiendo en su propio idioma. Eso no implica que no existan los otros grandes escritores que asumen la lengua del país de inmigración. Al fin y al cabo los dos grandes estilistas del siglo veinte de la lengua inglesa eran extranjeros: Conrad y Nabokov. Y, todavía a Conrad lo acusaban de que no hablaba bien el inglés...

M: Algo que me llamó la atención en una entrevista que le concedió a Cyberletras en Venezuela es que debido a su compromiso político usted dejó de escribir por un lapso de 10 años. ¿Cómo marca o afecta esto su espíritu de escritor, una vez que retoma la profesión?

SR: Realmente no podría saber cuál es el daño que recibí en no haber podido escribir diez años de mi vida, que fueron diez años que para un escritor siempre son clave, es decir, entre mis treinta y cinco 
y mis cuarenta y cinco, cuarenta y seis años. Creo que no tiene solución hacerse esa pregunta, ¿no? Para mí, lo importante fue reponer el tiempo perdido, y reafirmarme en mi vocación de escritor aun cuando yo todavía tenía compromisos políticos muy serios. En el 85 me hice la pregunta de que, bueno, si yo seguía sin escribir dejaba de ser escritor, y me puse a escribir con una disciplina muy estricta y logré seguir adelante con una novela que se llama Castigo divino, un plan muy ambicioso, una novela muy ambiciosa. Ahora, yo soy un escritor profesional y me llena mucho de satisfacción poder estar dedicado a escribir, que mi oficio sea escribir. Yo pienso que es muy excepcional en América Latina, y sobre todo en un país tan pobre como Nicaragua. Entonces, eso a mí me agudiza el sentido del deber (si lo podemos llamar de un modo), porque bueno, yo soy escritor, tengo una responsabilidad porque de alguna manera yo tengo el tiempo para escribir. Es un tiempo que alguien me está dando, mucha gente me está dando a mí, en esta especialización tan difícil en la sociedad nicaragüense. Mi idea es escribir y dejar una obra literaria otra vez para mi país, para Centroamérica, para América Latina, y eso solamente se consigue escribiendo.

M: Por cierto, en Castigo divino es donde usted incluyó la técnica del cine ¿verdad? ¿A qué se debe esto, había algo que en términos de la narrativa tradicional no se podía realizar?

SR: Como les decía, hablando de mis primeros recuerdos de mi infancia yo ahora lo veo como un paneo circular, alrededor de mi propia imagen, porque esta forma de ver yo la aprendí desde que tenía doce años. En mi memoria inédita cuento en un capítulo que se llama "Retrato de niño con ángel," la historia de la relación con mi tío, Ángel Mercado que era dueño del único cine del pueblo. A los doce años, él me nombró operador oficial, porque el operador era muy borracho y se peleaba, y mi tío llegó con mi padre a decirle que yo debía ser el operador, si de todas maneras vivía metido en la caseta de proyección y eso a mi padre no le gustó. Él siempre pensó que yo debía tener un título universitario y se horrorizó al pensar que yo me iba a quedar como operador del cine; pero al final permitió que yo fuera el operador con la condición de que no me pagara un solo centavo. Entonces, claro, yo desde los doce años comencé a ver muchas veces la misma película por la ventanilla de la caseta de 
proyección. Porque yo tenía que corregir la proyección, el sonido, que no se quemara, - en ese tiempo las películas se quemaban - . Y cuando la película se estropeaba tenía que sacar el rollo del aparato, llevarlo a la mesa devanadora, cortar, pegar con acetato, devolverla antes de que botaran a pedradas la caseta, porque era un cine al aire libre. Todo eso de ver desde plano extendido, plano cercano, medio plano, close-up, plano circular, todo eso se hizo parte de mi propio lenguaje visual. Entonces cuando yo comencé a escribir, eso era un instrumento que yo tenía ya instalado en mi disco duro, de ver como a través de la cámara cinematográfica. Eso por un lado como técnico, por otro lado, yo tengo una fascinación irreductible por el cine, es un vicio que adquirí de niño; los buenos vicios se adquieren en la infancia y tengo una gran nostalgia por el cine, que va a dar a mis novelas también. En Castigo divino yo comienzo con una película de Charles Laughton y de Ray Milland que es la historia de un envenenamiento; se está proyectando en un cine de León y en español se llama Castigo divino. Uno de los espectadores que está viendo la película sale a comentar al bar de la esquina (la Casa Prío en esta película), y él a la vez es periodista, y cuando va de regreso a su casa ve una escena de dos tipos que andan envenenado perros, y uno de ellos será el envenenador de la novela, que después va a envenenar a todos los miembros de una familia. Entonces, el cine es el leitmotif de esta historia que fue real, que se dio en 1933 en Nicaragua. Este personaje que se llama Oliverio Castañeda, un estudiante de derecho de Guatemala, que llegó a estudiar a León en Nicaragua con su esposa, y envenenó primero a la esposa y después a los miembros de una familia... Por lo que después se comienza a decir que "Esa película hay que prohibirla," que "Es un mal ejemplo". Entonces, la película, digamos en la novela, es sobre todo este proceso.

M: Esto hace el proceso de lectura un poco más complejo, ¿no? Requiere un mayor esfuerzo del público o lector...

SR: El público se va educando a una lectura siempre cada vez más compleja, por eso es que yo siempre soy un firme defensor de la escritura compleja, no de la escritura simple. Anoche vi la película Las horas, basada en la obra de Virginia Woolf, y la presentación es compleja pues el director comienza a desarrollar tres historias paralelas, y el público estaba tranquilo haciendo una lectura de tres historias 
paralelas que al final se juntan de alguna manera. Esto es lo que me parece fascinante en la narración, es decir, presentarle al lector siempre retos de complejidad, y ayudarlo a resolver estos retos, y no entregar todo masticado y servido, ese tipo de literatura no me interesa. Y yo sé que ésa es la literatura que va a tener cada vez más lectores en el futuro, en la medida en que el lector va desarrollando sus propias habilidades.

M: Desafortunadamente, las expectativas del público norteamericano en cuanto a la literatura latinoamericana son los clichés del realismo mágico, que si no tiene que ver con gente volando, pues no vende.

SR: Eso es una trampa porque desgraciadamente en Europa la literatura latinoamericana está en Francia matriculada por el realismo mágico. Si alguien no escribe sobre gente volando, no vende. Pero, bueno, es un accidente de mercado, esto no es la literatura, la literatura es otra cosa.

M: Y es muy difícil, pues al momento de publicar, volvemos a lo que se comentaba anteriormente, no te publican si no escribes ese tipo de narrativa, por ejemplo Fuguet es uno de los que pelean en contra de eso, él se subscribe a McOndo y no a Macondo, lo cual a mí me parece admirable.

SR: Y yo creo que el mismo García Márquez está de acuerdo con eso.

M: Entonces, una de las características claves de un gran escritor sería lo que usted acaba de decir, crear una literatura más compleja, cuyo valor se encuentra precisamente en el hecho de tener que volver a la lectura, releerla varias veces; es decir, un proceso que deja enriquecer y crecer al lector, tanto como al escritor, más que una simple lectura.

SR: Sí, porque creo que escribir es una aventura atemporal. Cuántos escritores no han sido reconocidos hasta después de su muerte, ahí está el caso de Borges. Borges no era leído en EE.UU. y ahora es un ejemplo, un maestro, ¿no? Tiene mucha influencia sobre escritores 
jóvenes, pero no era un escritor popular. Borges fue en su vida un escritor para escritores, después ha pasado a otro público; Saramago hasta antes que le dieran el Premio Nóbel no lo conocía nadie, ahora está en constante pues porque tiene el Premio Nóbel; es una ventaja, ¿no? para él, estupenda. Pero, bueno, puede ser que un escritor no sea conocido durante su vida o que no llegue al gran público durante su vida. Siempre recuerdo algo que dice Rubén Darío en el prólogo de Cantos de vida y esperanza, referido a esto de la literatura artística, o la literatura de masas, él dice: "Yo no soy un escritor para las masas, pero indefectiblemente voy a llegar a ellas". Esto me parece una definición estupenda, porque uno no escribe, no debe escribir para las masas, para que te entienda todo el mundo, o bajándote al nivel menos ilustrado para que la gente te entienda. Como esos manuales del escritor rápido, de la escritura rápida, que te dicen, "De cinco adjetivos escoge el más sencillo y el más común". Puede ser que no sea el mejor porque los adjetivos son claves en la literatura, un adjetivo te ilumina todo un párrafo y hay que saberlo escoger muy bien. Pero en la medida que el tiempo avanza y una literatura tiene calidad va a llegar a ser popular. ¿Quién iba a decir que Virginia Woolf iba a ser popular con Mrs. Dalloway? Ahora es un libro que todas las señoras leen. Y no es un libro fácil, está escrito en dos planos que no se conectan nunca y entonces es una lectura que presenta un desafío, pero ya es popular.

M: ¿Qué le parece esa combinación de ser escritor y profesor de literatura? ¿Cuáles serían las ventajas y las desventajas?

SR: Bueno, yo soy profesor de literatura en un sentido... en que a mí me gusta mucho enseñar, disfruto enseñar, hablar de literatura, me gusta mucho hacer los talleres con muchachos que les interesa ser escritores, no para enseñarles cómo se escribe, sino a abrirles caminos, enseñarles técnicas y sobre todo traerles la afición de leer, porque me parece que si no hay afición de lectura, no hay escritura. Pero esto yo lo hago en la Universidad de Maryland, o lo hago en seminarios en la escuela de periodismo de Gabriel García Márquez en Cartagena, donde soy también profesor por una semana, dos semanas al año en un seminario de periodistas que llegan de distintas partes, y hablo sobre periodismo y literatura. En la Universidad de Maryland, yo enseño una vez a la semana; realmente la carga de ser profesor todos 
los días no la aceptaría, porque competiría con mi disciplina de escritor, porque si fuera profesor de todos los días y tuviera que corregir muchos exámenes, bueno, yo tendría que hacerlo con responsabilidad; entonces me tendría que dedicar todo el tiempo, yo eso no lo podría hacer. A estas alturas de mi vida cuando yo sé lo qué es la responsabilidad de ser escritor, creo que la escritura es incompatible con cualquier otra disciplina. Tal como yo veo ahora la literatura, y si yo empiezo a escribir desde las ocho de la mañana hasta la una de la tarde todo es incompatible. Es mi profesión y todo lo demás se vuelve incompatible, porque si voy a dar una clase en la tarde la tengo que preparar en la mañana, no voy a llegar a improvisar enfrente de los estudiantes.

M: En su conferencia del jueves mencionó que uno de los temas que le atraen y le preocupan es el poder, ¿a qué se debe esto? ¿Es acaso la secuela de haber tenido una relación tan estrecha con la vida política? ¿O es el poder, o el abuso del mismo algo inherente en la realidad latinoamericana del siglo XX y por ende en su literatura?

SR: A mí me interesó el tema del poder creo que desde muy temprano en mi carrera de escritor, no porque hubiera pasado por el poder. En mi primer libro de cuentos, y que está en mis Cuentos completos publicados por Alfaguara (que no son tan completos porque del primer libro yo escogí los que me parecían que eran presentables, porque no toda escritura primeriza lo es), entonces, entre los que dejé de mi primer libro está uno precisamente que se llama "El poder." Es la historia de un juez nombrado por favores de un gamonal provincial de la política, que lo está esperando en su casa un domingo porque le ha dicho que va a pasar por ahí; entonces la mujer comienza a preparar comida, arregla la casa porque va a llegar "el poderoso," y al final de la espera y la expectativa de los vecinos, este hombre sólo se baja rápidamente del carro con el chofer porque va a recoger unas cabezas de plátano, unas naranjas que le tiene de regalo y le dice que va muy rápido porque va para Managua y no se queda. Entonces, este sentido del poder dependiendo de dónde alguien está colocado, el que está colocado más abajo o lo siente de un modo débil al que está más arriba. Luego en 1971 publiqué un libro de fábulas políticas que se llama De tropeles y tropelias, es un retrato del poderoso, del señor presidente, o su excelencia, como se llama en el resto de las narraciones 
que son breves. Yo me coloqué de alguna manera frente al poder en mi vida desde que era adolescente, porque entré en la política al mismo tiempo que en la literatura y también me coloqué en la literatura frente al poder, de una manera sarcástica, irónica. Al fin y al cabo les decía en la charla que yo nací bajo un Somoza, viví bajo otro Somoza, me fui al exilio bajo otro Somoza; es ineludible en lo que yo escribo, ¿no? Y el poder para mí siempre fueron los Somoza, y bueno, después vino el poder de la revolución, del cual yo fui parte, una pieza de ese poder; es algo que a mí me sigue fascinando. Si uno va a leer a Eurípides o a Sófocles siempre se encuentra que en la tragedia siempre está de por medio el poder, siempre la lucha por el poder.

M: Usted dijo estar de acuerdo con Susan Sontag en que no existe la sociedad utópica, entonces, ¿cómo contribuye Sergio Ramírez a mejorar la vida por medio de la literatura? ¿Está eso en su "agenda," consciente o inconscientemente? ¿La literatura que usted escribe se puede prestar a una causa o siente un compromiso como escritor además de como ciudadano?

SR: No sé si a través directamente de la literatura yo me pueda imponer la tarea de esclarecer a la gente y de crear grandes proyectos utópicos. Esto me parece que viene mucho de la literatura alemana desde Goethe, y que está presente en todos los grandes novelistas alemanes del siglo veinte. Esto de presentar un proyecto alternativo y utópico, de corregir el curso de la sociedad... Tengo mis dudas de que eso pueda ser posible en la literatura. Me parece que existe también el papel paralelo del ciudadano que Voltaire le concedía al escritor. Este concepto del intelectual que opina fue creado por Voltaire con su propio ejercicio, con su propia práctica; Voltaire se ocupaba de todos los casos de conflicto público, sobre penas de muerte impuestas injustamente, sobre gente que estaba presa, era un gran defensor de los derechos humanos, y escribió más de treinta mil cartas a quién correspondía, hablando de estos temas a los periódicos, a los gobiernos, a los poderosos. Me parece que en la medida que un escritor tiene renombre y es conocido, su voz es más oída y está obligado a opinar. Eso sí, yo siento que el escritor está obligado a opinar, uno puede vivir en una cámara de vacío sobre los grandes temas contemporáneos. Y si un escritor que es de renombre y alguien como ciudadano lee un pronunciamiento, se va a fijar en ese pronunciamiento. Eso sí, creo 
mucho en el papel ciudadano del escritor. Parece que apartarse de los temas, cerrar la persiana, apagar la luz y quedar en oscuridad no sirve para la escritura, uno no puede escribir en oscuridad. Yo tengo la ventana abierta al paisaje bastante ruinoso y desolado de mi país, y me angustio mucho con lo que ocurre en Nicaragua, es una pesadumbre constante; yo veo el deterioro del país y que no hay salida... Pero eso no me obliga a mí a decir bueno, me voy a poner a escribir una novela ahora para poner en claro lo que está pasando en Nicaragua, porque también me puede ocurrir que cuando esa novela se publica esos problemas de este momento ya envejecieron y van a venir otros. Un escritor no puede ser un cronista contemporáneo. A mí me parece que se corre mucho riesgo porque la vida, el presente se transforma muy rápidamente en pasado, y al fin y al cabo uno sólo puede escribir sobre el pasado; el pasado reciente, el pasado distante, pero al fin y al cabo uno está enfrentando siempre el pasado en la literatura. Ser profeta, me parece que algunos escritores lo lograrán, yo no me impongo eso como tarea, me parece que sería demasiado pretencioso.

M: Ya para concluir, ¿qué aspectos positivos considera usted nos puede traer la inevitable globalización? ¿Qué significa eso en realidad para América Latina?

SR: La globalización no se puede ver de manera global, hay que verla por piezas. Algunos de los aspectos de la globalización, sobre todo en el sector económico no son más que los viejos esquemas del capitalismo manchesteriano del siglo XIX: libertad de comercio, el trabajo servil para bajar los precios, las exportaciones. Eso me parece que es lo mismo, nada es nuevo. El movimiento de los capitales financieros tan brutal que se da hoy es tan negativo como los ajustes monetarios que se le imponen a los países con una enorme crueldad; eso no quiere decir que los países no deben disciplinarse a no gastar más de lo que tienen, eso obviamente está dentro de toda lógica. Pero me parece que la globalización tiene aspectos positivos, democráticos, la multiplicación de las posibilidades de las comunicaciones, la globalización de las comunicaciones es un hecho democrático, es accesible a mucha gente, es barato, la comunicación por Internet y por todos los demás medios de acceso a la información están a disposición de millones de gente, esto es un gran paso de la civilización. Ahora, claro, todo paso de la civilización puede servir para mal o 
para bien depende de cómo se utilice. La posibilidad de acceso a medios de cultura, entrar en sistemas de biblioteca, de galerías de arte, o de sitios donde se pueda bajar música, en fin, todas esas posibilidades son enormes no sólo para la distracción, sino también para la educación. Eso me parece un fenómeno de la civilización y sólo se puede comparar con el descubrimiento de la imprenta, que multiplicó las posibilidades de la comunicación al inventarse la imprenta. Pero el asunto de los instrumentos de transformación de la humanidad, esto que llamamos instrumentos de civilización, tiene mucho que ver con los valores éticos. A mí me parece que estamos viviendo una época muy desprovista de valores éticos, es más bien muy llena de valores antiéticos. Hace treinta años se creía mucho en la solidaridad, en el desprendimiento, el individualismo era demasiado exacerbado, para mí existe el individualismo creativo, uno crea como individuo. Pero la aplicación del individualismo en las relaciones sociales, y tratar de convertir las economías de mercado en sociedad de mercado va creando grandes atrocidades y desigualdades en el mundo. Entonces, con esta falta de valores éticos creo que hay gente que está en la cúpula del poder capaz de pensar que una parte de la humanidad es prescindible o va a llegar a ser prescindible, eso es lo que más me aterra, es decir, que la civilización se va a circunscribir a quienes pueden vivir en ella o tienen los medios para vivir en ella y el resto del mundo se queda en la oscuridad. Y estos efectos yo los veo muy patentes, el caso de África, o en segundo lugar quizá el de América Latina; pero en África, todo el abandono que hay de la organización social de África a la modernidad, la diseminación del SIDA es realmente terrible, afecta ya a más del $30 \%$ de la población, y esta lucha increíble que hay entre las grandes productoras de medicamentos de patente que se oponen a la producción de medicamentos genéricos en Sudáfrica. Todo esto me da la idea que una parte del mundo piensa que el resto del mundo no tiene por qué sobrevivir, y esto sí es un asunto de fondo, en la medida en que la globalización no sea una globalización verdadera que incluya a todo el mundo, y el derecho de todo el mundo de participar entonces en el fondo es un asunto verdaderamente ético.

M: ¿Y hay algo que se podría hacer para contrarrestar estos efectos devastadores? 
SR: Lo primero es no callarse, pero sin caer en las exacerbaciones del radicalismo que no interesa porque se vuelve un contraterrorismo verbal, sino tratar de abrir un debate. Y alguien me puede decir que de qué sirve abrir un debate, pero yo creo que las cosas se empeoran cuando todo mundo que piensa distinto se calla, pero el debate siempre es importante. 